\title{
POSSIBILIDADES E LIMITES DE HISTÓ RIAS DE VIDA POR MEIO DE DE POIMENTOS ORAIS NA HISTÓRIA DA FORMAÇÃO DE PROFESSORES
}

\section{Limits and possibilities of life history through oral interviews in teachers' development history}

\author{
Rosa Lydia Teixeira Corrêa ${ }^{[a]}$, Luciene Guiraud ${ }^{[b]}$ \\ [a]Professora do Programa de Mestrado em Educação da Pontifícia Universidade \\ Católica do Paraná (PUCPR), Curitiba, PR - Brasil, e-mail: rosa.correa@ pucpr.br \\ ${ }^{[b]}$ Mestranda em educação do Programade Mestrado em E ducação daPontifíciaUniversidade \\ Católica do Paraná (PUCPR), Curitiba, PR - Brasil, e-mail: luguiraud@ gmail.com
}

\section{Resumo}

A história de vida embora se manifeste como uma possibilidade de construção autobiográfica apresenta limites importantes que não podem ser descurados pelo pesquisador que a toma como procedimento de investigação (BOURD IEU, 2006), (LEVI, 2006). Bourdieu faz crítica contundente à história de vida e por isso aponta alguns limites. Este trabalho trata de proceder inicialmente à reflexão sobre essa crítica para apontar possibilidades de pesquisa de história de formação de professores por meio do uso de depoimentos orais. Tem em conta os mesmos alertas feitos ao uso da história de vida como construção historiográfica. Enfatiza a opção pelo uso de depoimentos orais em

Rev. Diálogo Educ., Curitiba, v. 9, n. 28, p. 671-686, set./ dez. 2009 
história de formação de professores, trazendo exemplos de alguns estudos que se mostraram promissores nesse sentido. São eles: (ALBUQUERQUE, 2008; CO RD EIRO, 2006; KLO D ZINSKI, 2008; PERO BELLI, 2008). Trata-se de um estudo vinculado a um projeto de pesquisa sobre história de formação de professores que tem a preocupação de centrar seus dados em depoimentos orais provenientes de professores para corroborar ou problematizar a legislação ou os projetos e currículos de formação, incluindo e, ao mesmo tempo, atribuindo também importância ao sujeito no processo histórico. Nesse sentido, da história da formação também fazem ou fizeram parte os sujeitos que nela estão ou estiveram inseridos. Por isso eles são entendidos como fontes importantes ao lado das tradicionalmente usadas em pesquisa histórica. Busca-se, portanto, pensar sobre a importância de apreender dos sujeitos como eles desenvolveram seu conhecimento durante sua formação profissional, e como ela se vincula ao ideário em voga nos meios educacionais em se tratando de história e espaço.

Palavras-chave: Formação de professores. D epoimentos orais. História da Educação.

\begin{abstract}
Life History as a methodology approach has been seeing as a possibility of an autobiografical construction but also shows some important limits in which the researcher cannot ignore when taking it as an investigation procedure(BORDIEU, 2006), (LEVI, 2006). Bordieu hardly criticizes this approach and this is why he points out some limits about it. This paper deals about a reflection on that criticism and points to possibilities of researches on history of teachers development through oral interviews as well as taking some previous researches on this kind of procedures. This paper also points out for the using of history of life as a historical method construction and emphasizes oral testimonies on history of teachers' development. It also brings some researches which had good results with this approach. Among them: (ALBUQUERQUE, 2008; CORDEIRO, 2006; KLODZINSKI, 2008; PEROBELLI, 2008). This study is linked to a research project about the history of teacher's development centering data through teachers' oral testimonies to corroborate legislation or development projects and curriculum, including and also giving importance to individuals on history process. Looking at this point through teachers' development history, individuals have such
\end{abstract}

Rev. Diálogo Educ., Curitiba, v. 9, n. 28, p. 671-686, set./ dez. 2009 
Possibilidades e limites de histórias de vida por meio de depoimentos orais na história da formação de professores

importance as well as other sources of investigation. This paper searches at this point of view the importance and participation of these individuals as well as how they had acquired knowledge during their professional development and how it is linked to educational ideas in vogue through time and history.

Keywords: Teachers'Development. Oral Interviews. History of Education.

\section{INTRODUÇÃO}

A história da formação de professores no Brasil tem sido contada por meio de estudos que privilegiam fontes documentais de caráter oficial como a legislação nas esferas federais e estaduais, a qual trata da regulamentação sobre a formação de professores no âmbito da educação. Como exemplos desses estudos podem ser citados os trabalhos de Candau (1987), Saviani (2005) e Tanuri (2000).

Tanuri (2000) aborda historicamente a formação de professores no Brasil desde a criação da primeira Escola Normal em Niterói em 1835 e fundamenta-se na legislação como apoio para realizar uma apreciação descritiva da atuação do Estado nesse campo. Saviani (2005), seguindo a mesmaperspectiva de Tanuri, traz contribuições destacando três momentos distintos e decisivos na história da formação de professores no Brasil. 0 primeiro momento passa pela reforma da Escola Normal do Estado de São Paulo; o segundo momento é representado pelas reformas dos anos 30 impulsionadas pelo movimento renovador e as exigências de profissionalização. Por último, a descaracterização do modelo de escola normal pelas Reformas do ensino superior e ensino de primeiro e segundo graus, por meio das Leis 5.540/ 68 e 5.692/ 71. Candau (1987), sob a perspectiva dos "Novos Rumos da Licenciatura", faz uma apreciação histórica desde a criação desses cursos nos anos de 1930.

Portanto é um estudo que abrange o percurso das licenciaturas, da criação àsuatrajetória, sob aégidedetrêsimportanteslegislações, asaber:aLD B 4.024/ 61, a Lei 5. 540/ 68 e a Lei 5.692/ 71 com destaque para a formação polivalente, ou seja, o professor está habilitado para ministrar diferentes disciplinas além da preparacão para atuar nas séries inicias de escolarização. As fontes usadas para apreciação da formação do professor são, sobretudo, legais.

Estudos mais específicos que se situam em caráter regional, além de fazerem uso destes documentos, utilizam relatórios de origens diferentes como os de professores, diretores escolares e de instrução,

Rev. Diálogo Educ., Curitiba, v. 9, n. 28, p. 671-686, set./ dez. 2009 
além de outros registros, entre eles as atas escolares. Neste sentido toma-se como referência os autores: G ondra (2005); Monarcha (1999); Peixoto (2005); Schaffrath (2002); Villela (2005).

Vilela (2005) preocupou-se com a formação e sua relação com a profissionalização desde a escola Normal da Corte, destacando a base científica que já se vislumbrava para essa formação nos anos de 1835. Gondra enfatiza esse mesmo caráter de formação no estudo que faz sobre a mesma instituição. Schaffrath (2002), também sob uma análise em que aponta para a proposta de formação científica da formação de professores, estuda a Escola Normal de Santa Catarina fundada em 1892, destacando o ideal de formação enciclopédica em consonância com o ideal burguês de educação. Monarcha (1999) não foge à regra ao vincular a criação da "Escola Normal da Praça" ao desenvolvimento urbano-industrial da cidade de São Paulo e, consequentemente, corresponder com a formação de professores às exigências sociais de escolarização. Peixoto (2005) analisa o processo de formação docente em Minas G erais centrando-se no exercício da profissionalização e das condições para esse exercício desde os saberes necessários à obtenção do diploma de professor, assim como o acesso e exercício da função.

As duas primeiras abordagens focam na formação desde a ótica oficial e, por assim dizer, do estado de modo crítico, ao passo que as demais fazem estudos desde o caráter regional, portanto mais específico, sem, no entanto, descurarem da legislação não sendo, entretanto, esta a exclusiva fonte adotada para estudo. Os trabalhos sobre escolas normais têm trazido importantes contribuições ao debate da formação ao fazerem essa circunscrição sob as bases de fontes bem diferenciadas, como fontes documentais encontradas em arquivos, tais como: relatórios de presidentes de províncias; relatórios de câmaras; relatórios de professores; relatórios de diretores de escolas, atas de reuniões, manuais, entre outros.

D essemodo, outras fontes precisam ser estudadas e comparadas aos documentos históricos oficiais, tendo as fontes orais como referências importantes para a apreciação metodológica.

A história da formação de professores utilizando essa gama de fontes precisaseranalisadadesdeaóticados professores. Essapossibilidade nos permite apreender, como por exemplo, as políticas de formação por meio da legislação desdobrada nos currículos, incorporadas ou não pelos professores em certo período histórico. Trata-se de procurar entender a consequência de processos formadores por meio tanto do ideal de formação quanto do conhecimento adquirido pelos professores. Os procedimentos com relatos orais se manifestam como uma possibilidade de realizar um estudo histórico sobre a formação de professores no Brasil

Rev. Diálogo Educ., Curitiba, v. 9, n. 28, p. 671-686, set./ dez. 2009 
Possibilidades e limites de histórias de vida por meio de

depoimentos orais na história da formação de professores

do ponto de vista regional ou nacional aliados à legislação e outras fontes documentais que permitem ampliar o olhar sobre a história da formação de professores para além dos diferenciados documentos escritos.

Com efeito, o que determina a escolha de uma metodologia de pesquisa são os pressupostos teóricos que a sustentam aliados à especificidade do problema a ser investigado. Assim, o estudo sobre formação de professores via relato oral apresenta-se como alternativa para a compreensão sobre os conhecimentos que o professor adquiriu durante sua formação e trajetória docente.

Esse procedimento como opção metodológicaapresenta-secomo uma opção importante, ou seja, ao propormos ouvir e analisar aspectos de histórias de vidas de pessoas creditamos a elas enquanto sujeitos, uma valiosa contribuição para o entendimento da realidade investigada.

Conhecer histórias de outras épocas, transitar entre narrativas de vida e documentos, penetrar, enfim, na vida de professores supõe, entre outras exigências, sensibilidade e rigor teórico-metodológico, daí considerarmos importante trazer à discussão os limites e possibilidades de lidarcom história devidaparaanalisarahistória de formação de professores.

Diante disso, o presente trabalho analisa os limites e as possibilidades do uso da metodologia de história de vida e aponta nesse âmbito as possibilidades do uso de depoimentos orais na pesquisa sobre formação de professores, levando em conta o ideal de formação sob 0 qual foram formados e os conhecimentos adquiridos, escolares ou não, no processo formador. Busca iluminar os aspectos ainda pouco conhecidos em relação ao conhecimento historicamente produzido sobre a formação de professores no Brasil. Mais do que fazer histórias de formação de professores pela história de vida pretendemos trazer uma breve problematização sobre a história de vida enquanto metodologia de pesquisa por meio de depoimentos orais tratando de aspectos pontuais da vida do sujeito de pesquisa, mas não no sentido autobiográfico.

\section{Sobre a histónia de vida: limites e possibilidades}

A oralidade, como recurso de testemunho, é utilizada desde a Antiguidade, contudo, desde o século XVIII, quando a História começou a se constituir enquanto disciplina acadêmica, a escrita é evidenciada, relegando-a ao segundo plano. E sse período é marcado pela constituição da burguesia como classe social que se tornou hegemônica e, consequentemente, assumiu o poder. Uma das características intrínsecas à referida classe, é a instituição da escola e da escrita como instrumento de dominação e consolidação de sua própria hegemonia.

Rev. Diálogo Educ., Curitiba, v. 9, n. 28, p. 671-686, set./ dez. 2009 
D esde a Revolução Francesa em 1789 até a década de quarenta do século vinte, a fonte escrita predominou como único instrumento válido de ser utilizado pelos historiadores. D e acordo com Prins (1992), essa prática é denominada como o período do preconceito para com a oralidade, pois "os historiadores vivem em sociedades alfabetizadas e, como muitos dos habitantes de tais sociedades, inconscientemente tendem a desprezar a palavra falada" (PRINS, 1992, p. 166).

No início da década de 1920 anuncia-se uma probabilidade de mudança nessa concepção, quando os historiadores franceses da escola dos Annaleselaboram críticasà historiografiapositivista, queelegeraosdocumentos escritos como únicosinstrumentos capazes de traduzirahistória. Isso fez com que 0 conceito de fontes históricas se ampliasse, dando aos historiadores novas perspectivas. Contudo, as fontes orais surgiram como possibilidade histórica somente duas décadas depois, nos Estados Unidos.

Segundo G attaz (1996), no período pós Segunda Guerra Mundial, os sociólogos da escola de Chicago passaram a utilizar "a entrevista, a observação participante e a biografia como meios privilegiados para a análise da realidade social" (GATTAZ, 1996, p. 238). Assim surge o que atualmente se denomina de história oral, procedimento que tem como fonte a oralidade. A partir de então várias tendências têm surgido na história oral: entrevistas com membros das classes dirigentes; a história dos excluídos por Thompson, na Inglaterra; a tendência psicológica e a arquivista, entre outras.

Conforme declara Barboza (2002), a história oral só surgiu no Brasil a partir da década de setenta, após o encontro promovido pela Fundação Ford, em parceria com a Fundação G etúlio Vargas, com especialistas em biblioteca e documentação. A ideia era articular um grupo que "pudesse criar uma infraestrutura de documentação para a pesquisa na área de Ciências Sociais" (BARBOZA, 2002). ${ }^{1}$

No Brasil, por causa do regime militar em que esse país se encontrava no período em que ocorreu o encontro daqueles especialistas, as gravações de conversas e entrevistas eram vistas como instrumentos de denúncia aos que possivelmente seriam as fontes de pesquisas, representando um entrave à história oral que então veio a se desenvolver somente com o fim do regime, no final da década de 1980.

A tualmente, considerada uma ferramenta da pesquisa qualitativa, o método de história oral é utilizado não só por historiadores, mas também por cientistas sociais, antropólogos, educadores e profissionais das diversas áreas das Ciências Humanas. Segundo aAssociação Brasileira de História O ral (ABHO),

Disponível em: <http:/ / www.primeiraversao.unir.br/ artigo105.html>. Acesso em: 18 jul. 2008.

Rev. Diálogo Educ., Curitiba, v. 9, n. 28, p. 671-686, set./ dez. 2009 
Possibilidades e limites de histórias de vida por meio de depoimentos orais na história da formação de professores

A gravação de entrevistas com testemunhas da história teve início na década de 1950, após a invenção do gravador à fita, na Europa, nos EUA e no México. A partir dos anos 1970, as técnicas da história oral difundiram-se bastante e ampliou-se 0 intercâmbio entre os que a praticavam. [...] O s anos 1990 assistiram à consolidação da história oral no meio acadêmico [...]. ${ }^{2}$

Assim, a história oral surgiu para valorizar as memórias de indivíduos, resgatando a tradição oral e buscando a variante de experiências vividas por atores sociais que a história tradicional deixou à margem.

D a mesma forma que a história oral é ferramenta da pesquisa qualitativa, a metodologia de história de vida está intrinsecamente ligada a ela. Paulilo (1999)3 explica que "[...] a história de vida (está) no quadro amplo da história oral que também inclui depoimentos, entrevistas, biografias, autobiografias." A autora considera ainda a história de vida:

[...] um instrumento privilegiado para análise e interpretação, na medida em que incorpora experiências subjetivas mescladas a contextos sociais. Ela fornece, portanto, base consistente para 0 entendimento do componente histórico dos fenômenos individuais, assim como para a compreensão do componente individual dos fenômenos históricos (PAULILO, 1999, 142-143).

G eralmente a história de vida de uma pessoa é obtida através de entrevistas com o pesquisador caracterizadas por uma conversa, uma interação, um encontro. Para Paulilo "[...]a entrevista pode ser construída como um 'encontro social', cujas características, entre outras, seria a empatia, a intuição e a imaginação; ocorre nela uma penetração mútua de percepções, sentimentos, emoções". (MARTINS; BICUD O, 1989 apud PAULILO, 1999, p. 143). D essa forma, enquanto ferramenta de captação, a entrevista é comum na construção de narrativas por parte de pesquisadores que utilizam o método de história de vida.

Cruikshank (2006, p. 151-156) explicita que a história oral "é uma expressão mais especializada, que em geral se refere aum método de pesquisa". A autora ainda complementa em seu estudo que "fatos pinçados aqui e ali nas histórias de vida dão ensejo a percepções de como um modo de entender 0 passado é construído, processado e integrado à vida de uma pessoa."

2 Disponível em: <http:/ / www.cpdoc.fgv.br/ abho/ asp/ dsp_APRE SENTAÇÃO .asp.>. Acesso em: 19 jul. 2008.

3 Disponível em: <http:/ / www.ssrevista.uel.br/ c_v2n1_pesquisa.htm>. Acesso em: 19 jul. 2008.

Rev. Diálogo Educ., Curitiba, v. 9, n. 28, p. 671-686, set./ dez. 2009 
Segundo Veyne (1998), a História deVida se utiliza da biografia centrada em indivíduos ou grupos so ciais. A especificidade dos fatos que o historiador escolhe para narrar pode ser buscada através das biografias.

Para Levi, no uso da biografia pelo historiador não se trata de reduzir as condutas a comportamentos-tipos, mas de interpretar as vicissitudes biográficas à luz de um contexto que as torne possíveis e, logo, normais. $\mathrm{O}$ autor declara em seus estudos que:

Essa utilização da biografia repousa sobre uma hipótese implícita que pode ser assim formulada: qualquer que seja a sua originalidade aparente, uma vida não pode ser compreendida unicamente através de seus desvios ou singularidades, mas, ao contrário, mostrando-se que cada desvio aparente em relação às normas ocorre em um contexto histórico que o justifica (LEVI, 2006, p. 176).

Pode-se apresentar-se como histórias orais ou relatos orais de vida, situações em que o próprio narrador referencia sua vida e experiência, e como depoimentos orais, quando o narrador informa fatos presenciados por ele. Nesse sentido, a metodologia pressupõe tanto possibilidades quanto limites.

Talvez os limites mais importantes a serem aqui analisados, em relação à história oral, possam ser descritos a partir de Bourdieu (2006) por meio das densas contribuições críticas que nos traz quando de suas reflexões sobre o que chama de ilusão biográfica. D iz ele:

A história de vida é uma dessas noções que do senso comum que entram como contrabando no universo científico; inicialmente, sem muito alarde, entre os etnólogos, depois, mais recentemente, com estardalhaços entre os sociólogos. Falar em história de vida é pelo menos pressupor - e isso não é pouco - quea vidaé uma história e que, como ao título de Maupassant, U ma V ida ${ }^{4}$, uma vida é inseparavelmente o conjunto dos acontecimentos de uma existência individual concebida como uma história e 0 relato dessa história. [...] (BO RD IEU, 2006, p. 183).

Importa destacar que esse autor faz uma análise critica à biografia, e ao mesmo tempo critica rigorosa e contundentemente esse modo de fazer história. Embora não se constitua tarefa fácil depreender

4 (Grifos do autor).

Rev. Diálogo Educ., Curitiba, v. 9, n. 28, p. 671-686, set./ dez. 2009 
Possibilidades e limites de histórias de vida por meio de depoimentos orais na história da formação de professores

dos argumentos do autor percebe-se que um dos elementos reside no fato de que a história não pode ser contada como se fosse um romance tal o caráter de previsibilidade que pode ter tanto para quem a escreve quanto para quem a narra. Assim, para ele:

Produzir uma histónia de vida, tratar a vida como uma história, isto é, como o relato coerente de uma sequiência de acontecimentos com significado e direção, talvez seja conformar-se com uma ilusão retórica, uma representação comum da existência que toda uma tradição literária não deixou e não deixa de reforçar (BO URDIEU, 2006, p. 185).

Essa ideia de previsibilidade ou o "fato de que vida constitui um todo, um conjunto coerente eorganizado, quepode edeveser apreendido..." (BOURD IEU, 2006, p. 184), antepõe também a de linearidade emanada de uma subjetividade que pretende trazer à tona seus encantos e desencantos, sem deixar de demarcar as intencionalidades postas no próprio conteúdo da narrativa. Assim, para Bourdieu (2006, p. 184):

Essa vida organizada como uma história transcorre, segundo uma ordem cronológica que também é uma ordem lógica, desde um começo, uma origem, no duplo sentido de ponto de partida, de início, mas também de princípio, de razão de ser, de causa primeira, até seu término, que também é um objetivo. $O$ relato seja ele biográfico ou autobiográfico, como o do investigado que "se entrega" a um investigador, propõe acontecimentos que, sem terem se desenrolado, sempre em sua estrita sucessão cronológica (quem já colidiu histórias de vida sabe que os investigados perdem constantemente o fio da estrita sucessão do calendário), tendem ou pretendem organizar-se em seqüências ordenadas segundo relações inteligíveis. 0 sujeito e o objeto da biografia (o investigador e o investigado) têm de certa forma o mesmo interesse em aceitar 0 postulado do sentido da ex istência ${ }^{5}$ narrada (e, implicitamente, de qualquer existência).

D esse modo, Bourdieu nos alerta para alguns dos limites do uso desse recurso metodológico. Há que não se descurar do aspecto estritamente subjetivo, bem como realizar uma espécie de crivo sobre o fato de que o sujeito que se dispõe a narrar sua história de vida ou

Grifos do autor.

Rev. Diálogo Educ., Curitiba, v. 9, n. 28, p. 671-686, set./ dez. 2009 
mesmo parte dela, pode fazer no uso dos dados a serem externalizados, para que se tornem públicos. É necessário que se fique atento ao que é importante salientar e se fazer conhecer, e desta forma atentar para: [...] os atos dos pensamentos da vida cotidiana, das dúvidas e das incertezas, do caráter fragmentário e dinâmico da identidade e dos momentos contraditórios de sua constituição (LEVI, 2006, p. 169). Não se deve esquecer também que há os limites impostos pela memória.

Por outro lado, levando em conta os limites acima apontados, há a possibilidade de trabalhar não exclusivamente com a história oral no sentido de construir narrativas autobiográficas, mas de utilizar esse recurso para a obtenção de dados so bre aspectos específicos da trajetória de vida do sujeito, ou seja, sua formação profissional. A este respeito especificamente trataremos melhor no item seguinte.

A história de vida, ou dos depoimentos orais como recurso metodológico de pesquisa, se ocupa em conhecer e aprofundar conhecimentos sobre determinada realidade, recuperando experiências devida obtidas através de conversas com pessoas, por meio de entrevistas que, ao focalizarem lembranças pessoais, constroem também uma visão mais concreta da dinâmica de funcionamento e das várias etapas da trajetória de um grupo social, de um sujeito na pesquisa, ponderando esses fatos pela sua importância em suas vidas.

Essa possibilidade metodológica possibilita ao pesquisador romper com o encerramento acadêmico que transforma a entrevista em simples suporte documental, pois os depoimentos podem ser aprofundados levando-se em conta os propósitos dos estudos que deseja realizar. Com efeito, sintetiza,

[...] a riqueza inesgotável do depoimento oral em si mesmo, como fonte não apenas informativa, mas, sobretudo, como instrumento de compreensão mais ampla e globalizante do significado da ação humana; de suas relações com a sociedade organizada, com as redes de sociabilidade, com o poder e o contrapoder existentes, e com os processos macroculturais que constituem o ambiente dentro do qual se movem os atores e os personagens deste grande drama ininterrupto - sempre mal decifrado - que é a História Humana (ALBERTI, 1990, p. 8).

O que se pode obter é resultado do encontro entre sujeitos que devem estar conscientes da objetividade do encontro e também do que comporta em subjetividade. Neste encontro, se ganha maior dimensão quando há real parceria entre entrevistador e entrevistado, possibilitando

Rev. Diálogo Educ., Curitiba, v. 9, n. 28, p. 671-686, set./ dez. 2009 
Possibilidades e limites de histórias de vida por meio de

depoimentos orais na história da formação de professores

a ambos construírem uma relação de adesão ao processo de questionamentos, compreensão, críticas e, por fim, reconstituição do objeto da pesquisa, sendo o resultado, fruto desta relação social.

Nesse sentido, não se pode estabelecer um roteiro de entrevista rígido a ser seguido em vários encontros, pois em cada um deles novas informações e conhecimentos são acrescidos, e, segundo Demartini (1992, p. 47): "é um processo acumulativo, que resulta da escuta atenta e da reflexão sobre as informações que vão sendo coletadas, e que implicam em novos questionamentos nas entrevistas subseqüentes." Entretanto, embora se deva deixar o narrador livre para falar o que quiser, é necessário aprofundar determinados aspectos, relevantes para a pesquisa, que vão surgindo no decorrer da entrevista, sem perder de vista os objetivos previamente traçados.

A coleta de dados obtidos por meio de depoimentos orais, como parte de uma história de vida se traduz, também, em uma ocasião em que o entrevistado reflete sobre sua vida, sobre sua trajetória, antes mesmo da realização da entrevista. (LANG , 1996). Percebe-se, neste processo, que "[...] a verdadeira imagem do passado perpassa veloz", e que o passado "só se deixa ficar, como imagem que relampeja irreversivelmente, no momento em que é reconhecido." (BENJAMIN, 1994, p. 224).

Nesta opção metodológica, a fonte é sempre uma invocação à memória, reconstruindo um passado pela perspectiva do presente e marcado pelo social. Assim, é preciso entendê-la numa perspectiva que vai além de um relato de fatos, uma maneira de se chegar ao conhecimento de fatos vivenciados num dado momento histórico em que somente documentos escritos não poderiam revelar por si só todos os sentidos presentes num determinado meio social.

Meihy (1996, p. 10) considera afonte oral como uma "percepção do passado como algo que tem continuidade hoje e cujo processo histórico não está acabado". Em sua concepção, ela "garante sentido social à vida de depoentes e leitores que passam a entender a sequência histórica e a sentirem-se parte do contexto em que vivem".

Neste sentido, também Chartier (2002, p. 84) refere-se ao relato como uma singularidade da história, pelo fato de manter uma relação específica com a verdade, pois as construções narrativas pretendem ser "a reconstituição de um passado que existiu".

Thompson (1992, p. 22) define-a como uma prática social possivelmente geradora de mudanças que transformam tanto o conteúdo quanto a finalidade da história, pois, para ele, a história oral altera 0 enfoque da própria história e revela novos campos de investigação, podendo derrubar barreiras entre os sujeitos.

Rev. Diálogo Educ., Curitiba, v. 9, n. 28, p. 671-686, set./ dez. 2009 
D essaforma, por setratar deumaabordagem que cruza, transporta e desloca informações, estabelece relações de contraste e tensões entre testemunhos provindos de diferentes sujeitos, promove diálogos, rompendo fronteiras em busca de outras possibilidades de inteligibilidade. A presenta maneiras de perceber e praticar a pesquisa exigindo do pesquisador outras habilidades que alimentem uma sensibilidade e uma abertura para 0 diferente, 0 plural, o inusitado, 0 não revelado que muitas vezes pode corroborar ou contestar o que está escrito.

Entretanto, e dentro das possibilidades, o debate a respeito da legitimidade da metodologia de história de vida não está encerrado por serem mantidas posições de alguns historiadores que a desqualificam como método de pesquisa. Há a compreensão de que o depoimento oral limitaseao "diz-quediz-que", ao questionamento dapróprianomenclatura "história oral" em favor de "fontes orais". Para Ferreira (2002, p. 328-329):

A principal críticaà expressão "história oral" liga-se ao fato de quenas sociedades modemasnão existeum discurso oral puro, eà perspectiva de que um depoimento oral só ganhasuaplena significação em confronto com o documento escrito. Além disso, a "histónia oral" trariaembutidaaintenção de seconstituir em disciplina capaz de uma interpretação científica, escamoteando-se assim sua finalidade de produzir fontes que serão objeto de análises e interpretações. Finalmente, critica se a noção de que a história oral seria uma outra história, uma história alternativa, mais comprometida com a militância política do que com o rigor dos métodos acadêmicos. $\mathrm{Na}$ visão desses críticos, a história oral, tanto dos vencidos como dos vencedores, estaria marcada pordeformações ideológicas.

Ainda é apontada, criticamente, a dificuldade de controle da comunidade acadêmica so bre as fontes produzidas a partir de entrevistas, por serem exclusividade dos pesquisadores e sua consulta limitada aos demais interessados. Para a solução desse caso específico, estão sendo criados acervos de depoimentos orais produzidos por seus pesquisadores, que disponibilizam as narrativas e possibilitam também o recebimento earquivamento de depoimentos produzidos por pesquisadores externos.

Assim sendo, vale ressaltar a necessidade de estudos consistentes sobre a prática e a própria metodologia da história de vida, pois é um instrumento importante que possibilita uma melhor compreensão das representações de grupos ou indivíduos nas diferentes sociedades. D esta forma, optamos pela ideia e prática de depoimentos orais, justamente pelo fato de não pretendermos fazer biografia de educadores, mas obter dados de formação profissional obtidos num certo tempo e espaço históricos.

Rev. Diálogo Educ., Curitiba, v. 9, n. 28, p. 671-686, set./ dez. 2009 
Possibilidades e limites de histórias de vida por meio de

depoimentos orais na história da formação de professores

\section{Depoimentos orais e formação de professores: contribuições para a história da formação}

D entre os limites e as possibilidades trazidas pela historiografia, os limites e as possibilidades de trabalhar com a história de vida como metodologia no campo da história e em particular da história da educação, optamos em trazer dessa apreensão a ideia de relatos e/ ou depoimentos orais cujo propósito em termos de procedimento de pesquisa, não é o de contar a história de formação de professores por meio da história de vida, mas trazer elementos do processo de formação num certo tempo histórico utilizando depoimentos orais. Neste sentido, a entrevista tem 0 fito de estabelecer cruzamento entre dados de diferentes fontes levando em conta 0 que se pretende em termos de pesquisa. Esse procedimento tem sido usado em dissertações (ALBUQUERQUE , 2008; CO RD EIRO, 2006; KLODZINSKI, 2008; PEROBELLI, 2008).

Desse modo consideramos relevante trazer alguns estudos onde este recurso foi utilizado por meio de depoimentos orais e assim saber mais sobre uma problemática de pesquisa em particular. 0 estudo de Perobelli (2008), embora não seja de natureza histórica utiliza depoimentos orais para resgatar no processo de formação de professores com formação superior a cinco anos e analisar quais os saberes que influenciaram na atuação profissional destes professores. Neste caso foi necessário recuperar elementos de história de vida, sem, no entanto fazer história de vida, construir biografia, já que os depoimentos incidiam sobre sua formação profissional tendo em vista a atuação na docência em ensino superior de cursos de Teologia Luterana.

0 estudo realizado por Klodzinski (2008), um dos mais elucidativos nesse sentido, aborda so bre a educação nova na historiografia brasileira, enfoca de modo quase unânime ter tido esta dimensão nos meios escolares brasileiros desde os anos de 1930, particularmente depois do manifesto de 1932. Foram realizadas entrevistas com professoras que se formaram e atuaram nas décadas de 1950 e 1970, o que se constatou não foi bem isso. O ideário escolanovista parece não ter tido essa dimensão, destacadamente em parte do interior do Paraná de onde são as professoras que deram seus depoimentos. Elas não tiveram formação segundo os princípios dessa educação pelo menos naformação enquanto normalistas.

A pesquisa desenvolvida por Albuquerque (2008), de natureza histórica, trouxe por meios de depoimentos orais contribuições para reflexão sobre o curso de Educação Física entre 1960 e 1990, na perspectiva do poder do corpo sob o qual se assenta um ideário formador voltado para a higienização e eugenia cuja concepção foi reafirmada em depoimento dos professores entrevistados no estudo.

Rev. Diálogo Educ., Curitiba, v. 9, n. 28, p. 671-686, set./ dez. 2009 
0 estudo de Cordeiro (2006) também foi importante nesse sentido. Usando depoimentos orais, a autora discutiu sobre a instituição da Nomenclatura Gramatical Brasileira, destacadamente em Curitiba com objetivo de saber sobre sua aceitação e uso por parte de professores de língua portuguesa entre os anos de 1950 e 1960. Os depoimentos demonstraram ter havido resistências por parte dos professores que viam nessas normas um caráter excessivamente técnico ainda que ela tenha sido incorporada pelos livros didáticos de língua portuguesa.

E sses exemplos são importantes para mostrar que a história da formação de professores também pode ser contada pelos sujeitos que dela participaram. Significa pensar em possibilidades de saber o que eles fizeram com os objetos que foram destinados, parafraseando Bourdieu (1983). Neste caso, os conhecimentos que lhes foram destinados e do qual participaram, bem como sobre as ideias que sedimentaram a formação historicamente falando.

\section{CONSIDERAÇÕES FINAIS}

As reflexões trazidas são frutos de primeiras aproximações metodológicas sobre a necessidade do uso de relatos orais em estudos históricos. Relatos orais ou depoimentos orais não podem ser analisados fora da problemática teórica que incide sobre a história de vida no campo da história. Uma apreciação sobre isso foi realizada no item dois deste trabalho onde procuramos situar essa discussão por meio dos limites e possibilidades do uso desse recurso metodológico, destacando nossa opção pelos depoimentos orais, justamente por não estarmos preocupados em proceder a uma construção autobiográfica detalhada, mas trazer do depoente elementos de sua vida, ou de um período de sua vida do qual nos interessa um assunto em particular, neste caso, sua formação para ser professor ou professora.

No item três trouxemos alguns estudos, sobremaneira de natureza histórica, retirados de depoimentos orais com a finalidade de resgatar aspectos da formação de professores e que foram relacionados com a legislação, historiografia, enfim, com a teoria específica pertinente a cada um deles, quer para reafirmá-los, quer para problematizá-los.

Trata-se de um trabalho vinculado ao desenvolvimento de um projeto de pesquisa que tem buscado aprimorar teoricamente os procedimentos metodológicos usados em seu interior, ao mesmo tempo em que pretende tornar centrais os depoimentos orais em estudos preocupados com a história de formação de professores.

Enfim, a pertinência dessa opção metodológica poderá ser mais bem avaliada no processo de desenvolvimento da pesquisa, do ponto de vista de seu aspecto operacional, bem como da própria análise dos resultados a serem obtidos.

Rev. Diálogo Educ., Curitiba, v. 9, n. 28, p. 671-686, set./ dez. 2009 
Possibilidades e limites de histórias de vida por meio de depoimentos orais na história da formação de professores

\section{REFERÊNCIAS}

ALBERTI, V. H istónia oral: a experiência do CPD O C. Rio de Janeiro: FGV, 1990. ALBUQUERQUE, L. R. Concepção de educação e saberes na formação de professores em Educação Física e a relação entre saber e poder. 2008. 188 f. Dissertação (Mestrado em Educação) - Pontifícia Universidade Católica do Paraná, Curitiba, 2008.

AMAD 0, J.; FERREIRA, M. M. Usos \& abusos da história oral. 8. ed. Rio de Janeiro: FGV, 2006.

ASSO CIAÇÃO BRASILEIRA DE HISTÓ RIA ORAL. Apresentação. Disponível em: <http:/ / www.cpdoc.fgv.br/ abho/ asp/ dsp_APRESENTAÇÃO.asp>. Acesso em: 19 jul. 2008.

BENJAMIN, W. Magia e técnica, arte e política: ensaios sobre literatura e história da cultura. Tradução Sérgio Paulo Rouanet. São Paulo: Brasiliense, 1994.

BARBOZA, J. J. História oral e hermenêutica. Revista Primeira Versão, Porto Velho, n. 105, ago. 2002. Disponível em: <http:/ / www.primeiraversao.unir.br/ artigo105.html>. Acesso em: 18 jul. 2008.

BOURDIEU, P. A ilusão biográfica. In: AMAD 0, J.; FERREIRA, M. M. Usos \& abusos da histónia oral. 8. ed. Rio de Janeiro: FGV, 2006.

BOURD IEU, P.; ORTIZ, R. Pierre Bourdieu. São Paulo: Ática, 1983.

CHARTIER, R. A história cultural: entre práticas e representações. 2 ed. Tradução Maria Manuela Galhardo. Rio de Janeiro: D IFEL, 2002.

A visão do historiador modernista. In: AMAD 0, J.; FERREIRA, M. M. Usos \& abusos da história oral. 8. ed. Rio de Janeiro: FGV, 2006.

CORDEIRO, L. Concepção de educação, formação de professores e ensino da Língua Portuguesa: história e memória dos anos de 50 e 60 do século XX. 2006. 80 f. D issertação (Mestrado em Educação) - Pontifícia Universidade Católica do Paraná, Curitiba, 2006.

CRUIK SHANK, J. Tradição oral e história oral: revendo algumas questões. In: AMAD O, J.; FERREIRA, M. M. Usos \& abusos da história oral. 8. ed. Rio de Janeiro: FGV, 2006.

DEMARTINI, Z. B. F. Trabalhando com relatos orais: reflexões a partir de uma trajetória de pesquisa - reflexões sobre a pesquisa sociológica. Caderno Textos. São Paulo: CERU, 1992. n. 3.

FERREIRA, M. M. Entre-vistas: abordagens e uso da história oral. Rio de Janeiro: FGV, 1994.

Rev. Diálogo Educ., Curitiba, v. 9, n. 28, p. 671-686, set./ dez. 2009 
História, tempo presente e história oral. 2002. Disponível em: <www2.uel.br/ cch/ cdph/ arqtxt/ Historia_tempopresenteehistoriaoral.pdf>. Acesso em: 21 jul. 2008.

KLOD ZINSKI, A. F. A E scola N ova e o ideário de formação de professores no Paraná entre as décadas de 1950 e 1970. 2008. 148 f. D issertação (Mestrado em Educação) - Pontifícia Universidade Católica do Paraná, Curitiba, 2008.

LANG, A. B. S. G. História oral: muitas dúvidas, poucas certezas e uma proposta. In: MEIHY, J. C. S. B. (O rg.). (Re) introduzindo história oral no Brasil. São Paulo: USP, 1996. (Eventos).

L E V I, G . Usos da biografia. In: AMAD O, J.; FERREIRA, M. M. Usos \& abusos da história oral. Rio de Janeiro: FG V, 2006.

MEIHY, J. C. S. B. Manual de histónia oral. São Paulo: Loyola, 1996.

PAUliLlo, M. A. S. Pesquisa qualitativa e a história de vida. Serv. Soc. Rev., Londrina, v. 2, n. 2, p. 135-148, 1999. Disponível em: <http:// www.ssrevista.uel.br/ n1v2.pdf>. Acesso em: 19 jul. 2008.

PEROBELLI, R. Os saberes docentes dos professores de teologia das Instituições Teológicas da Igreja Evangélica de confissão Luterana no Brasil. 2008. 149 f. Dissertação (Mestrado em Educação) - Pontifícia Universidade Católica do Paraná, Curitiba, 2008.

PRINS, G. Histónia oral: a escrita da história: novas perspectivas. São Paulo: UNESP, 1992.

QUEIROZ, M. I. Relatos orais: do "indizível" ao "dizível". In: PAULILO, M. A. S. A pesquisaqualitativa ea históniadevida. Serv. Soc. Rev., Londrina, v. 2, n. 1, 1999. Disponível em: <http:/ / www.ssrevistauel.br/ c_v2n1_pesquisahtm>. Acesso em: 19 jul. 2008.

THOMPSON, P. A voz do passado: história oral. Tradução Lólio Lourenço de Oliveira. Rio de Janeiro: Paz e Terra, 1992.

VEYNE, P. Como se escreve a histónia e Foucault revoluciona a história. Brasília: UnB, 1998.

Recebido: 10/ 01/ 2009

Received: 01/ 10/ 2009

Aprovado: 15/ 03/ 2009

A pproved: 03/ 15/ 2009

Revisado: 15/ 09/2009

Reviewed: 09/ 15/ 2009

Rev. Diálogo Educ., Curitiba, v. 9, n. 28, p. 671-686, set./ dez. 2009 